Thorax (1975), 30, 357.

\title{
Growth and development of human fetal trachea and lung in immune-deprived mice
}

\author{
L. M. C O B B \\ Department of Environmental Physiology, Huntingdon Research Centre, Huntingdon PE18 6ES
}

\begin{abstract}
Cobb, L. M. (1975). Thorax, 30, 357-359. Growth and development of human fetal trachea and lung in immune-deprived mice. Trachea and lung parenchyma from human fetuses were transplanted subcutaneously into immune-deprived mice. After seven to 10 weeks they were removed for histological examination. It was found that the tissues continued to grow and develop along similar lines to those which they would have followed in utero.
\end{abstract}

Adult human bronchial submucosal gland has been cultured successfully in vitro by Sturgess and Reid (1972). These authors used this technique in their research into the pharmacology of submucosal gland secretion. Higgins and Ellis (1973) have used similar in vitro techniques for the study of the activity of respiratory tract viruses on human fetal trachea. The limitations of in vitro studies are acknowledged by workers using organ cultures of human adult and fetal respiratory tract. The organ cultures frequently do not survive successfully beyond the first week (Trowell, 1959).

Where long-term experimental studies on human respiratory tract are to be made it is necessary to turn to in vivo methods for the support of this complex tissue. Lance and Medawar (1968) showed that human skin could be grafted onto suitably immune-suppressed mice and survive for at least eight weeks. More recently it has been shown that human tumours, including carcinoma of the bronchus, will survive in immunedeprived mice for periods of up to nine months (Cobb and Mitchley, 1974). In order to study the long-term effect of chemicals and drugs on the human respiratory tract, we have been investigating the hetero-transplantation of fetal lung into immune-deprived mice. This is a report of these investigations. We observed that when the human tissues were implanted subcutaneously into immune-deprived mice they proliferated extensively and also developed in the same way and at approximately the same rate as they would have done had the fetus remained in utero.

\section{MATERIALS AND METHODS}

Male CBA/lac mice were used as recipients for the fetal tissue. The sex of the mice was chosen to match the sex of the fetus.

The technique of immune-deprivation was that used for tumour xenografts (Cobb, 1973). The mice were thymectomized at 4 weeks of age. Four weeks later they were given $900 \mathrm{r}$ whole-body irradiation at $60 \mathrm{r}$ per minute using a $220 \mathrm{kv} X$-ray machine, hvl $0.4 \mathrm{~mm} \mathrm{Cu}$, focal distance $100 \mathrm{~cm}$. As this dose of radiation would have proved lethal without a bone marrow graft, within six hours of irradiation each mouse received $5 \times 10^{6}$ syngeneic femoral bone marrow cells intravenously. The fetal tissue was implanted two to four weeks after the irradiation and bone marrow replacement.

The fetuses that were the source of the organs for transplantation were between 14 and 17 weeks advanced and had, until the time of removal from the uterus, developed normally. The trachea, main bronchi, and lung parenchyma were removed aseptically from six fetuses and within four hours approximately $9 \mathrm{~mm}^{3}$ of each tissue was implanted subcutaneously into one or both flanks of the prepared mice. One hundred and sixteen mice received transplants. Transverse sections of the trachea or main bronchus from each fetus were transplanted into one flank of six groups of eight to 10 mice (56 mice). Lung parenchyma from each of six fetuses was transplanted into both flanks of groups of 10 mice $(50$ mice). Representative areas of lung were taken from all fetuses for histological examination to confirm the absence of any pathology or abnormal development.

The 116 mice bearing the transplants were killed between seven and 10 weeks after implantation. During this period the grafts of lung parenchyma had 


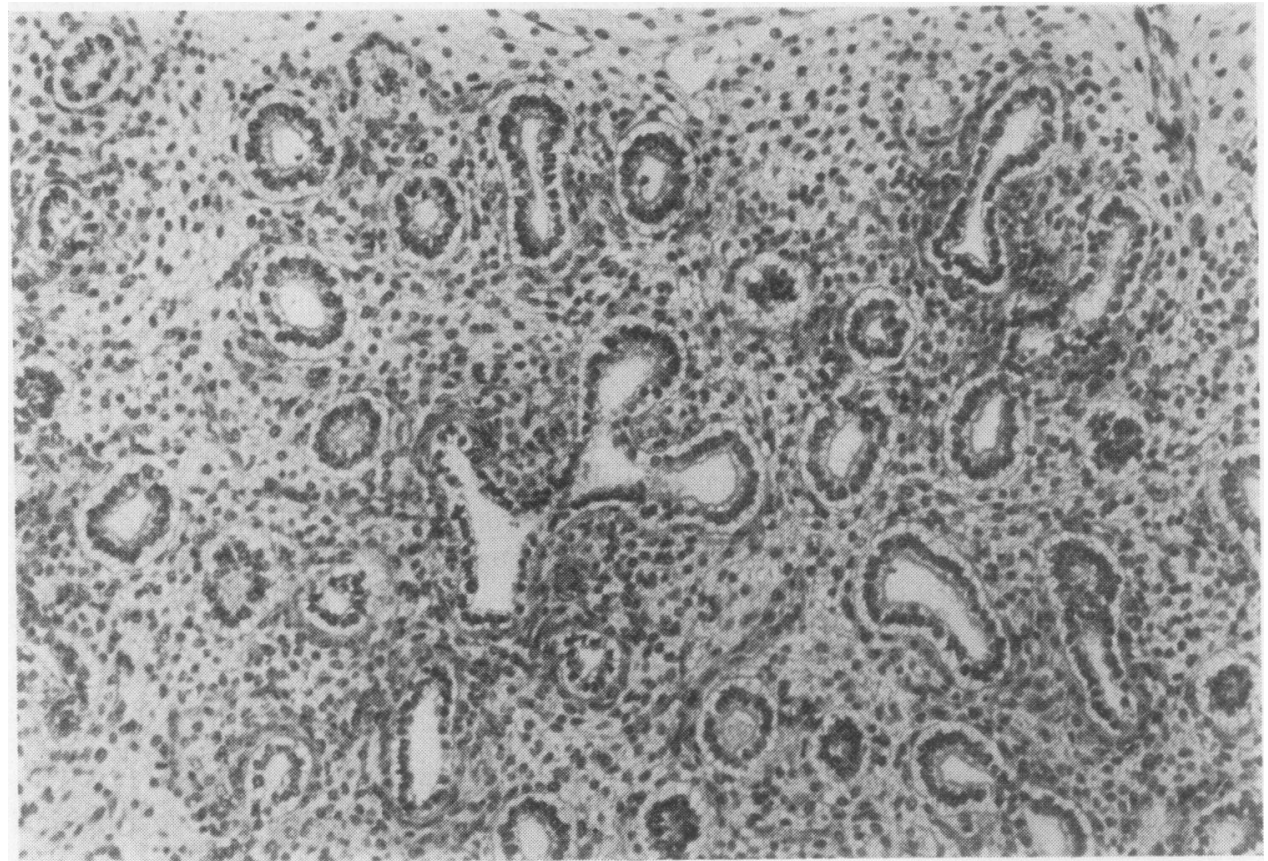

FIG. 1. Human fetal lung in approximately the 17 th week of gestation ( $H$ and $E \times 100$ ).

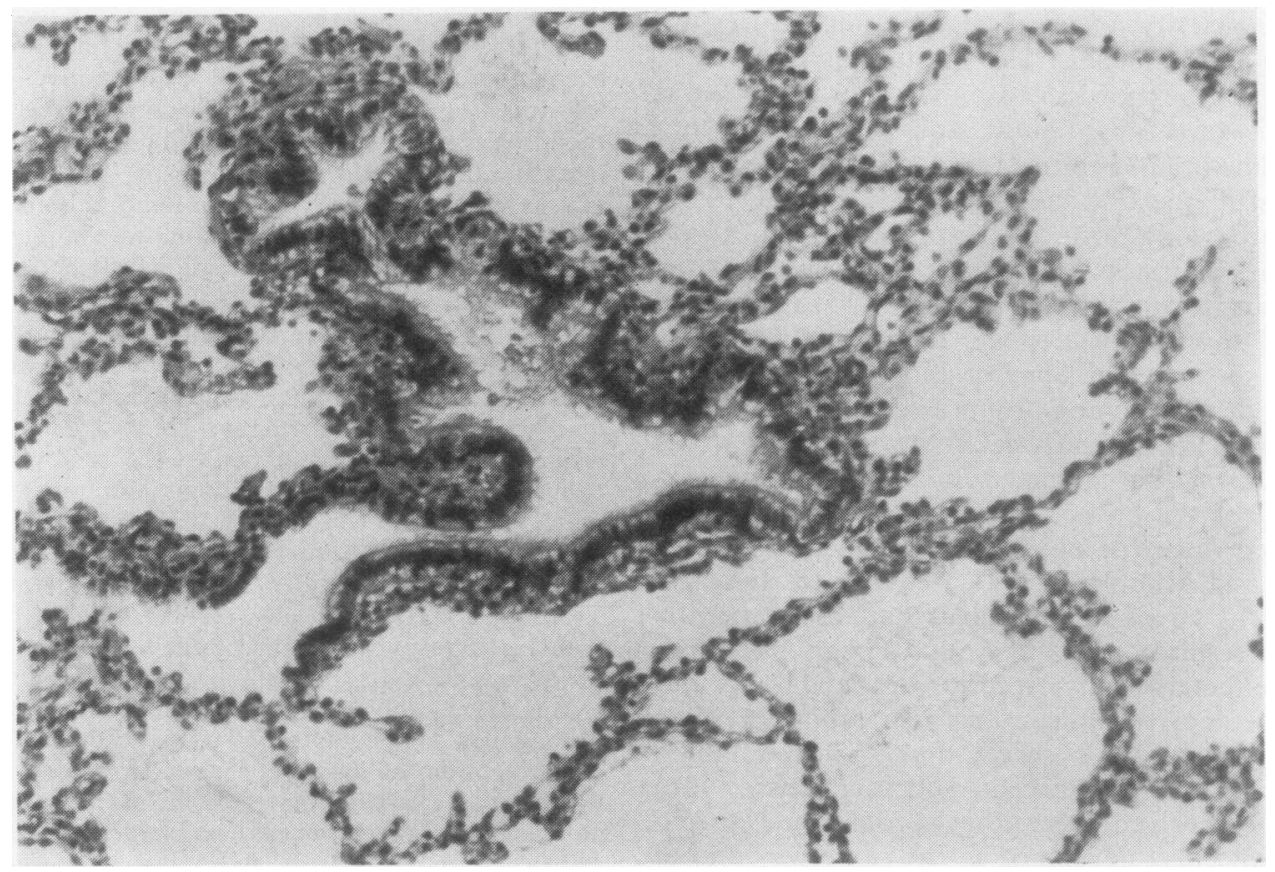

FIG. 2. The same lung as Fig. 1 after eight weeks' growth subcutaneously in an immunedeprived mouse ( $H$ and $E \times 100$ ). 
grown to form masses up to $1 \mathrm{~cm}^{3}$ in size on the flanks of the animals. All transplants were removed and fixed in Bouin's solution, sectioned, and stained with haematoxylin and eosin.

\section{RESULTS}

All tissue layers of the trachea and bronchus continued to develop and grow following transplantation into the mice, but growth was not uniform and the tubular structure of the trachea and bronchus became distorted. At the time of implantation the epithelium had not begun to form the anlage of the submucosal glands but this differentiation was observed in tissues examined after seven to 10 weeks implantation. In some implants acinar structures had developed in the proximal part of the developing submucosal glands. When the period of implantation was added to the age of the fetus, it was found that at least part of the trachea and bronchus was at the same stage of development that it would have reached had it been in the intact fetus in utero. The cartilaginous plates of the trachea and bronchus continued to grow in the mice but frequently grew in bizarre shapes.

At the time of transplantation (14-17 weeks intra-uterine life) of the lung parenchyma, the epithelial cells lining the bronchioles were ciliated. The respiratory bronchioles were beginning to differentiate by branching of the terminal bronchioles, and the alveoli had not begun to form (Fig. 1). When the lung parenchyma was removed from the mice, the alveoli were clearly identifiable (Fig. 2). The alveoli had 'expanded' and in some areas gave the appearance of lungs that had expanded following inhalation. It is presumed that these alveoli contained fluid, or a gel, although this was not always apparent from the histological sections. Areas of the lung had developed in the mouse in approximately the same way and in the same period of time as if the fetus had remained intact and in utero. The volume of 'normally' developed lung ranged from 10 to $80 \%$ when grafts in different mice were compared. The remaining areas of lung tissue were inhibited in their development. The blood vessels supporting the centre of the lung grafts ran adjacent to the conducting airways. It was not possible to know if they originated from the graft or the host.

\section{COMMENT}

Charnock and Doershuk (1973) have divided fetal lung development into three phases: first, a glandular phase during which time the bronchial divisions are established; secondly, a canalicular phase (beginning around the sixteenth week) in which the respiratory portion of the lung is delineated and vascularized; and, beginning 24 to 26 weeks the final, alveolar phase. In the present experiments the canalicular and early alveolar phases were passed in the subcutaneous tissue of the mouse. The xenografted human fetal lung fragments continued to grow and develop in much the same way as they would have done in utero except for some disorientation. It appears, therefore, that the immune-deprived mouse is a suitable vehicle for the prolonged support of human fetal respiratory tract.

This research was carried out in the Department of Pathology, Chester Beatty Research Institute, London, supported by grants from the Medical Research Council and the Cancer Research Campaign. I wish to thank Mrs. Jana Wood for her technical assistance and Miss Rosemary Ellis for the histological preparations.

\section{REFERENCES}

Charnock, E. L. and Doershuk, C. F. (1973). Developmental aspects of the human lung. Pediatric Clinics of North America, 20, 275.

Cobb, L. M. (1973). The behaviour of carcinoma of the large bowel in man following transplantation into immune-deprived mice. British Journal of Cancer, 28, 400.

and Mitchley, B. C. V. (1974). The growth of human tumours in immune-deprived mice. European Journal of Cancer, 10, 473.

Higgins, P. G. and Ellis, E. M. (1973). Further observations on the use of organ cultures in the study of acute respiratory-tract infections. Journal of Medical Microbiology, 6, 177.

Lance, E. M. and Medawar, P. B. (1968). Survival of skin heterografts under treatment with antilymphocyte serum. Lancet, 1, 1174.

Sturgess, J. and Reid, L. (1972). An organ culture study of the effect of drugs on the secretory activity of the human bronchial submucosal gland. Clinical Science, 43, 533.

Trowell, O. A. (1959). The culture of mature organs in a synthetic medium. Experimental Cell $R e$ search, 16, 118.

Requests for reprints to: Dr. L. M. Cobb, The Department of Environmental Physiology, Huntingdon Research Centre, Huntingdon PE18 6ES. 